\title{
ТЕНДЕНЦИИ ИЗМЕНЕНИЯ ПОТЕНЦИАЛА КОРМОВЫХ РЕСУРСОВ ЖИВОТНОВОДСТВА ПОД ВОЗДЕЙСТВИЕМ ФАКТОРОВ ИННОВАЦИОННОГО РАЗВИТИЯ
}

\author{
(c) 2020 Васильченко Марианна Яковлевна \\ кандидат экономических наук, старший научный сотрудник \\ Институт аграрных проблем Российской академии наук, Россия, Саратов \\ E-mail: mari.vasil4enko@yandex.ru
}

Исследованы тенденции изменения потенциала производства и переработки кормовых ресурсов животноводства России под воздействием факторов инновационного развития. Предложены индикаторы инновационного профиля животноводства, производства и переработки кормовых ресурсов животноводства, характеризующие возможности формирования инновационных продуктовых цепочек.

Определены перспективы формирования кормовой базы с учетом структурных сдвигов в организации кормопроизводства и процесса цифровизации сельского хозяйства. Обоснованы сценарии потребности животноводства в кормах, в том числе с учетом вызовов пандемии коронавируса.

Ключевые слова: агропромышленный комплекс, государственная поддержка, инновационный профиль, животноводство, кормовые ресурсы, пандемия коронавируса

\section{Введение}

Стратегическая цель российской экономики на экспортно-ориентированный рост не может быть реализована без значительного повышения конкурентоспособности продукции агропромышленного комплекса. Кормовые ресурсы оказывают существенное влияние на процесс создания добавленной стоимости в сельскохозяйственном производстве, определяя возможности формировании инновационных цепочек и роста эффективности производства продукции в соответствии с технологическими вызовами. Повышение инновационного уровня отраслей животноводства, совершенствование генетического потенциала предопределяет необходимость внедрения конкурентоспособных технологий кормопроизводства, в максимальной степени использующих отечественные кормовые ресурсы. Сохраняющаяся высокая доля импортных компонентов комбикормов значительно повышает стоимость конечной продукции. По данным Минсельхоза, доля иностранных аминокислот, используемых в кормопроизводстве, составляет примерно 80\%, кормовых антибиотиков - 85-95\%, ферментных препаратов $-70-90 \%$, витаминов - 100\%, белковых кормов животного происхождения - около 30\%, микроэлементов - 90\% [1]. Преодоление высо- кой импортной зависимости на рынке кормовых добавок, витаминов, ферментов, белковых кормов будет иметь следствием значительные структурные сдвиги в сельскохозяйственном и обрабатывающем сегментах цепочки создания добавленной стоимости, а также достижение ресурсной независимости аграрного производства [2]. Поэтому важнейшими задачами, поставленными в проекте подпрограммы «Развитие производства кормов и кормовых добавок для животных» выступают: улучшение конверсии корма на основе повышения их инновационной и структурной сбалансированности; стимулирование научных разработок по созданию новых технологий производства комбикормов и их сырьевых компонентов. Трансфер инновационных технологий производства кормов будет способствовать снижению импортной зависимости в данных сегментах кормопроизводства, что особенно актуально в периоды экономических кризисов, вызванных самыми различными причинами, в том числе и пандемией коронавируса 2020 года.

Результаты исследования. Состояние кормовых ресурсов страны во многом определяется возможностями трансформации посевных сельскохозяйственных культур в целях производства необходимого объема различных видов кормов, 
исходя из потребностей животноводческих отраслей. Экспортная направленность развития агропродовольственного комплекса России подтверждается ожидаемыми темпами увеличения объемов животноводческой продукции к 2025 году на $15,8 \%$ (16,15 млн. т в живом весе). Хотя достижение запланированного уровня будет осуществляться в основном за счет свиноводческой и птицеводческой подотраслей, существенный прирост продукции должен быть получен в молочном и мясном скотоводстве. С 2000 по 2018 гг. посевные площади сельскохозяйственных культур в целом по РФ сократились на 5,7\% (рис. 1).

За период 2000-2019 гг. посевные площади кормовых культур в РФ уменьшились на $46,7 \%$ и составили 15417,1 тыс. га; доля их в общей посевной площади сельскохозяйственных культур снизилась с $34,1 \%$ до $19,1 \%$. Подобная ситуация во многом объяснялась понижательной тенденцией российского животноводства; поголовье крупного рогатого скота в рассматриваемом периоде уменьшилось на $32,4 \%$. Вместе с тем важной тенденцией является изменение структуры посевных площадей в направлении увеличения таких культур как рапс и соя, потребность в которых длительное время компенсировалась за счет импортных поставок сои. В настоящее время потребность в сое на кормовые цели животноводства составляет около 8 млн. т [3], а потребность в соевом шроте оценивается в 5 млн. т в год [4]. По данным Росстата, в 2019 г. валовой сбор сои составил 4,36 млн. т, а рапса $-2,06$ млн. т (+71,6 тыс. т.).

В рассматриваемом периоде посевные площади под рапсом увеличились в 2,6 раза и по оценке Росстата, в 2020 году составят 1,7-1,72 млн. га; это отражает тенденцию повышения спроса на рапсовый жмых и шрот в молочном скотоводстве и свиноводстве, что особенно актуально в кризисный период, когда в связи с пандемией коронавируса усложняются экспортно-импортные операции, а повышение курса доллара заметно увеличивает стоимость импорта. Организация переработки семян рапса также позволяет снизить себестоимость кормов за счет использования более дешевого собственного сырья. Для отдельных регионов России действуют специальные программы производства и переработки рапса; предусмотрено выделение субсидий для организации производства рапса и сои тем регионам, которые выбрали в качестве приоритетов возделывание рапса и сои. Финансирование будет обеспечиваться за счет перераспределения бюджетных средств на реализацию федерального проекта «Экспорт продукции АПК».

Снижение поголовья КРС имело следствием улучшение показателя обеспеченности сенокосами и пастбищами: в 2000 г. в расчете на голову КРС приходилось 3,3 га, а в 2019 г.- 4,1 га. Вместе с тем ускоренное развитие мясного

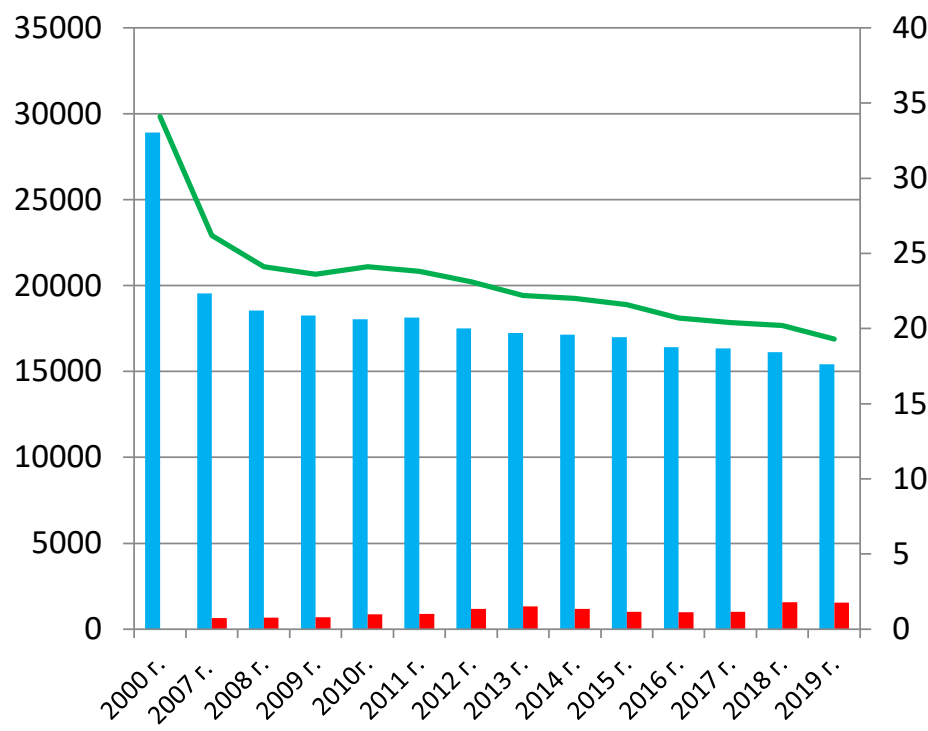

40

35

30

25

20

15

10

—д вес кормовых в общей площади, \% ( правая шкала),

Рuc. 1. Динамика посевных площадей кормовых культур в России (2000-2019 гг.) 
скотоводства неизбежно потребует расширения площадей сенокосов и пастбищ, что возможно осуществить при дополнительном вовлечении в оборот неиспользуемых сельскохозяйственных угодий, удельный вес которых на начало 2019 г. составлял $16,7 \%$ от общей их площади [5].

Важное направление повышения конкурентоспособности продукции - рост сбалансированности перерабатываемых кормов с учетом требований конечного инновационного продукта. Развитие процесса цифровизации сельского хозяйства будет иметь следствием прозрачность компонентов и происхождения кормов. Следует отметить такую принципиально новую технологию как кормоинжиниринг (инновационное управление кормовыми ресурсами предприятия), в основе которого - выбор максимально эффективной стратегии использования кормовых ресурсов, включая и альтернативные источники сырья, с возможной корректировкой рационов с помощью интеллектуальной системы применения премиксов и высокотехнологичных кормовых средств [6].

Постоянный дефицит кормового зерна в течение длительного периода компенсировался за счет использования продовольственных видов зерновых культур. Высокая доля зерновых в рационах животных и птицы связана с рисками постоянного изменения конъюнктуры на зерновом рынке. Если в европейских странах на долю зернового сырья в составе комбикормов приходится 45-50\%, то в России - 65-70\%; доля шротов и жмыхов, наоборот, в три-четыре раза меньше, чем в странах с развитым аграрным сектором [7]. Одной из причин перерасхода зерна выступает несбалансированность комбикормов по протеиновому и аминокислотному составу. В настоящее время потребность животноводства в белковых концентратах оценивается на уровне 800 тыс. тонн; фактически потребляется 180-190 тыс. тонн. Как следствие, на производство животноводческой продукции затрачивается в 2-3 раза больше кормов по сравнению с развитыми странами, а потребности комбикормовой промышленности в кормовом белке как важнейшем компоненте обеспечиваются лишь на 60-65\% [8].

Кормовая несбалансированность в большей степени характерна для молочного скотоводства. По данным за 2016 г., удельный вес полнорационных комбикормов в общем объеме составил: для КРС $-42 \%$, свиней $-58 \%$, птицы $-92 \%$. В странах Европы эти показатели были равны, соответственно: 80\%, 93\%, 98\% [9]. Сбалансированность по кормам в определенной степени может служить индикатором инновационности производства, поскольку характеризует структурные изменения технологий кормления. Например, увеличение объемов производства премиксов для крупного рогатого скота в 2017-2019 гг. на 75\% свидетельствует о повышении инновационного уровня кормления. Отсутствие комплексной государственной поддержки научного сопровождения развития отечественных биотехнологий для производства комбикормов в течение длительного периода выступало тормозом развития и увеличивало риски роста цен. Высокая зависимость от импорта привела к резкому повышению цен в условиях пандемии коронавируса на кормовые компоненты (в феврале-марте 2020 года цены на кормовые витамины возросли на 30-50\%).

Достижение сбалансированности комбикормов при снижении доли фуражного зерна возможно в результате увеличения переработки неиспользуемых отходов растениеводства, животноводства, побочных продуктов пищевой и перерабатывающей промышленности; сокращения объемов экспорта белкового растительного и животного сырья.

В комбикормовой промышленности за последние годы наблюдается заметное увеличение объемов производства и повышение инновационного уровня, хотя технологическая зависимость от импортного оборудования остается достаточно высокой: 66\% в 2018 году. Важным пунктом подпрограммы «Развитие производства кормов и кормовых добавок для животных» является стимулирование российских разработок и технологий, что будет способствовать трансферу технологий. Для измерения инновационного профиля производства и переработки кормовых ресурсов животноводства использовались индикаторы, рассчитанные по данным Федеральной статистики. Их сравнение с другими видами деятельности позволило определить место кормовых ресурсов в инновационных цепочках животноводческой продукции.

За 2007-2016 гг. объем инновационных товаров по направлению «Производство кормового микробиологического белка, премиксов, кормовых витаминов, антибиотиков, аминокислот и ферментов» увеличился на $42,5 \%$. О перспек- 
Таблица 1. Индикаторы инновационного профиля животноводства и кормопроизводства

\begin{tabular}{|c|c|c|}
\hline \multirow{2}{*}{ Индикаторы инновационного профиля } & \multicolumn{2}{|c|}{ Годы } \\
\hline & 2017 & 2018 \\
\hline \multicolumn{3}{|c|}{ Отгружено инновационных товаров, тыс. руб. } \\
\hline Инновационные товары животноводства в расчете на т мяса, руб. & 1144 & 1460,5 \\
\hline $\begin{array}{l}\text { Инновационные товары животноводства в расчете на условную } \\
\text { голову скота, руб. }\end{array}$ & 428,6 & 565,8 \\
\hline $\begin{array}{l}\text { Инновационные товары молочного скотоводства в расчете на голо- } \\
\text { ву КРС, руб. }\end{array}$ & 106,6 & 113,1 \\
\hline $\begin{array}{l}\text { Инновационные товары свиноводства в расчете на голову свиней, } \\
\text { руб. }\end{array}$ & 207,3 & 438,2 \\
\hline $\begin{array}{l}\text { Инновационные товары птицеводства в расчете на } 1 \text { голову птицы, } \\
\text { руб. }\end{array}$ & 17,1 & 16,2 \\
\hline $\begin{array}{l}\text { Инновационные готовые корма в расчете на условную голову скота, } \\
\text { руб. }\end{array}$ & 216,9 & 327,5 \\
\hline $\begin{array}{l}\text { Инновационный кормовой белок в расчете на условную голову } \\
\text { скота, руб. }\end{array}$ & 134,3 & 186,1 \\
\hline \multicolumn{3}{|c|}{$\begin{array}{c}\text { Удельный вес затрат на технологические инновации в общем объеме отгруженных товаров, } \\
\text { выполненных работ, услуг, \% }\end{array}$} \\
\hline $\begin{array}{l}\text { Производство готовых кормов для животных, содержащихся на } \\
\text { фермах }\end{array}$ & 2,0 & 1,6 \\
\hline $\begin{array}{l}\text { Производство кормового микробиологического белка, премиксов, } \\
\text { кормовых витаминов, антибиотиков, } \\
\text { аминокислот и ферментов }\end{array}$ & 5,6 & 4,6 \\
\hline Животноводство & 0,7 & 0,6 \\
\hline $\begin{array}{l}\text { Разведение молочного крупного рогатого скота, производство сы- } \\
\text { рого молока }\end{array}$ & 0,4 & 0,7 \\
\hline Разведение свиней & 0,6 & 0,3 \\
\hline Разведение сельскохозяйственной птицы & 0,9 & 1,2 \\
\hline
\end{tabular}

Рассчитано по данным Федеральной статистики.- Режим доступа: https://www.fedstat.ru/

тивности данного вида деятельности свидетельствует и более высокий удельный вес затрат на технологические инновации (4,6\% в 2018 году) в сравнении с животноводческой продукцией. Согласно Федеральной научно-технической программе развития сельского хозяйства на 2017-2025 годы, использование инновационных технологий производства высококачественных кормов и кормовыхдобавок позволитуменьшить импортозависимость на 25\%. В 2017-2018 гг. индикатор отгруженных инновационных готовых кормов в расчете на условную голову скота увеличился на 51\%, а инновационного кормового белка - на 38,6\%. По отдельным видам животноводческой продукции прослеживалась разнонаправленная динамика отгруженных инновационных товаров. Например, по животноводству в целом увеличение составило $132 \%$; в молочном скотоводстве - 106,1\%; в свиноводстве - 200,1\%, птицеводстве - 94,7\%. Предложенные индика- торы, наряду с показателями инновационности производства и затрат ресурсов могут использоваться для оценки уровня сформированности инновационных продуктовых цепочек. С учетом ранее рассчитанного индикатора инновационности затрат кормов на производство мяса свиней (90\%) можно сделать вывод о более высокой степени завершенности инновационного цикла в цепочке производства свинины.

Выявленные тенденции развития кормовой базы животноводства учитывались при обосновании сценариев потребности животноводства в кормах. Первый сценарий предполагает увеличение к 2025 году объемов производства животноводческой продукции в соответствии с требованиями Госпрограммы развития сельского хозяйства, а также сохранение достигнутого в 2018-2019 гг. уровня кормоемкости. По второму сценарию прогнозируется снижение кормоемкости за счет инновационной составляющей. 
Таблица 2. Сценарии потребности основных видов животноводческой продукции в комбикормах, тыс. т

\begin{tabular}{|l|c|c|c|c|}
\hline \multicolumn{1}{|c|}{ Виды продукции } & 2018 г. & \multicolumn{3}{|c|}{ Прогноз на 2025 год } \\
\cline { 3 - 5 } & & Сценарий 1 & Сценарий 2 & Сценарий 3 \\
\hline $\begin{array}{l}\text { Потребность в комбикормах, на производство } \\
\text { мяса птицы }\end{array}$ & 11000 & 12000 & 11400 & 11500 \\
\hline $\begin{array}{l}\text { Потребность в комбикормах на производство } \\
\text { яиц }\end{array}$ & 6200 & 6900 & 5900 & 6700 \\
\hline Всего потребность птицеводства в комбикормах & 17300 & 18900 & 17300 & 18200 \\
\hline $\begin{array}{l}\text { Потребность в комбикормах на производство } \\
\text { молока, тыс. т }\end{array}$ & 7200 & 8200 & 6800 & 7300 \\
\hline $\begin{array}{l}\text { Потребность в комбикормах, на производство } \\
\text { мяса КРС }\end{array}$ & 5800 & 6300 & 5900 & 5500 \\
\hline $\begin{array}{l}\text { Всего потребность в комбикор-мах на молоко и } \\
\text { мясо КРС }\end{array}$ & 13000 & 14500 & 12700 & 12800 \\
\hline $\begin{array}{l}\text { Потребность в комбикормах на производство } \\
\text { мяса свиней }\end{array}$ & 18000 & 24300 & 20300 & 20800 \\
\hline $\begin{array}{l}\text { Итого потребность основных видов животновод- } \\
\text { ческой продукции в комбикормах }\end{array}$ & 48300 & 57700 & 50300 & 51800 \\
\hline
\end{tabular}

Третий сценарий определяет потребность животноводства в кормах с учетом вызовов пандемии коронавируса и сокращения объемов производства животноводческой продукции при сохранении фактического уровня кормоемкости (таблица 2).

По первому сценарию потребность основных видов животноводческой продукции в комбикормах составит 57,7 млн. т, по второму - 50,3 млн. т, третьему - 51,8 млн. т. Если первый и второй сценарий отражают целевые установки объемов производства животноводства Госпрограммы развития сельского хозяйства до 2025 года, то по третьему сценарию предполагается умеренный рост производства мяса птицы (на 2\% к уровню 2018 г.); мяса свиней - на 8\%; молока - на 4,8\%. Производство мяса КРС, напротив, уменьшится на 7,1\%. Кроме того, последствия пандемии коронавируса и возможное сокращение объемов финансирования отраслей АПК вызовут трудности импортозамещения необходимых компонентов кормов. Поэтому расход фуражного зерна на производство комбикормов по третьему сценарию отражает сохраняющуюся несбалансированность и удельный вес зернового компонента на уровне 65-70\%. Уменьшение кормоемкости продукции по второму сценарию вследствие инновационного ресурсного замещения позволит сэкономить до 6 млн. т. фуражного зерна.

\section{Библиографический список}

1. Кулистикова T., Максимова E. Минсельхоз разработал программу развития кормовой индустрии. - URL: https://www.agroinvestor.ru/analytics/news/32736-minselkhoz-razrabotal-programmu-razvitiya-kormovoyindustrii/.

2. Потапов А.П. Обеспечение ресурсной независимости аграрного производства в контексте продовольственной безопасности России // Проблемы прогнозирования. 2019. № 5. С. 120-129.

3. Рынок протеиновых ингредиентов комбикормов.-URL: https:/www.tsenovik.ru/articles/obzory-i-prognozy/ rynok-proteinovykh-ingredientov-kombikormov/.

4. Минсельхоз оценивает потребность животноводов в соевом шроте на уровне 5 млн. тонн. - URL: https:// pticainfo.ru/news/? ELEMENT_ID=52181.

5. Доклад о состоянии и использовании земель сельскохозяйственного назначения Российской Федерации в 2018 году.- М.: ФГБНУ «Росинформагротех», 2020. - 340 c. URL: http://mcxac.ru/upload/iblock/c0c/c0ccac7d4 0b051325fcef23aa79a3e00.pdf. 
6. Кормоинжиниринг - инновационный подход в управлении кормовыми ресурсами.- URL: https://www. dairynews.ru/news/kormoinzhiniring-innovatsionnyy-podkhod-v-upravlen.html.

7. Орлова Н. Плюс 1,1 млн. тонн по кормам. Особенности развития комбикормовой промышленности // Агроинвестор, 10 января 2019.- URL: https://www.agroinvestor.ru/markets/article/31005-plyus-1-1-mln-tonn-pokormam/.

8. Стартует высокотехнологичный проект «Протеин России».- URL: https://www.dairynews.ru/news/.

9. Основные тенденции и среднесрочные сценарии развития производства комбикормовой продукции.URL: http://mcx.ru/upload/iblock/ 20f/20f22f553 eb26f7341b3fbfcd89071a3.pdf. 